\title{
NASOLABIAL RHABDOMYOSARCOMA: A RARE CASE
}

Ashfaque Ansari' ${ }^{1}$, Rajeev Pastapur², Suma Moni Mathew ${ }^{3}$

\section{HOW TO CITE THIS ARTICLE:}

Ashfaque Ansari, Rajeev Pastapur, Suma Moni Mathew. "Nasolabial Rhabdomyosarcoma: A Rare Case". Journal of Evolution of Medical and Dental Sciences 2014; Vol. 3, Issue 16, April 21; Page: 4150-4154,

DOI: $10.14260 /$ jemds/2014/2411

ABSTRACT: Rhabdomyosarcomas (RMS) are among the most common soft-tissue tumors in children. These tumors are derived from mesenchymal tissue with a tendency toward myogenic differentiation that probably originates from immature and highly invasive satellite cells associated with the embryogenesis of skeletal muscle. The diagnosis is made by microscopic analysis and auxiliary techniques such as immunohistochemistry, electron microscopy, cytogenetic analysis, and molecular biology. We report here a case of nasolabial RMS in a 5-year-old child and provide an updated review of the literature, focusing mainly on the clinicopathological aspects, diagnosis and treatment of RMS of the head and neck.

KEYWORDS: Childhood, nasolabial, Rhabdomyosarcoma, immunohistochemistry.

INTRODUCTION: Rhabdomyosarcomas (RMS) is the most common intracranial solid tumors in children. ${ }^{1}$ RMS are malignancies derived from primitive mesenchymal tissues that exhibit a tendency toward myogenic differentiation and probably originate from satellite cells associated with the embryogenesis of skeletal muscle. ${ }^{1}$ RMS was initially described by Weber in 1854 . The head and neck are the most frequently affected regions, followed by the orbit (35\% of cases), trunk and extremities, intra-abdominal organs and genitourinary tract (23\%). There are reports of cases arising in oral tissues, which correspond to 10 to $12 \%$ of all head and neck RMS and mainly involve the tongue, palate and oral mucosa. ${ }^{2}$ As a result of their aggressive neoplastic behavior characterized by immature and highly invasive cells, RMS are associated with high rates of recurrence and generalized metastases through the hematogenic and/or lymphatic routes. The diagnosis is generally made by microscopic analysis and auxiliary techniques such as immunohistochemistry, electron microscopy, cytogenetic analysis, and molecular biology. ${ }^{3}$ We report here a case of nasolabial RMS in a 5-year-old child and provide an updated review of the literature, focusing mainly on the clinicopathological aspects, diagnosis and treatment of RMS of the head and neck.

CASE REPORT: A 5 year old boy came to the ENT OPD with a painless swelling over his left nasolabial region. His parents reported that they had noticed the swelling progressing in size since 2 months following a history of trauma to the same site.

On inspection, there was facial asymmetry over the left side due to expansion of swelling on that side of the nose obstructing that side of the nasal passage. There was no alteration in color of overlying skin. On palpation, a soft - firm, non-tender mass of size $3 \times 2 \mathrm{~cm}$ over the left nasolabial area and free from the underlying alveolus but not from the overlying skin. Intra orally the swelling had the same color as the normal mucosa and involved the alveolar mucosa from the left central incisor to the $1^{\text {st }}$ left molar. Rest ENT and systemic examination was insignificant.

On investigation, Ultrasonography of the face demonstrating a well circumscribed and ovoid lesion that contains a hyperechoic texture, possibly indicating an abscess with hypoechoic areas 


\section{CASE REPORT}

compatible with a cystic cavity. Computed tomography showed a homogeneous mass in the left part of the maxilla involving the left nasal cavity and limited to the soft tissue (fig. 1). This was suggestive of nasolabial cyst with hematoma. Rest of his routine blood investigations were within normal limits.

An excisional biopsy via intra-oral approach was done, intra -operatively the lesion had infiltrative appearance to the soft tissue (fig. 2) and the lesion was removed in Toto. Postoperatively a week later, a left submandibular lymph node, non-tender and firm in consistency of size $2 \times 2 \mathrm{~cm}$ was noticed (fig. 3). The nasolabial biopsy send for histopathological examination revealed non-cohesive cell aggregates with alveolar pattern areas with predominantly slit like spaces surrounded by irregular round to oval spindle shaped pleomorphic cells invading surrounding muscle tissue (fig. 4). On Immunohistochemistry; the tissue were positive for neuron specific Enolase (fig. 5), Desmin (fig. 6) and MYOD 1.

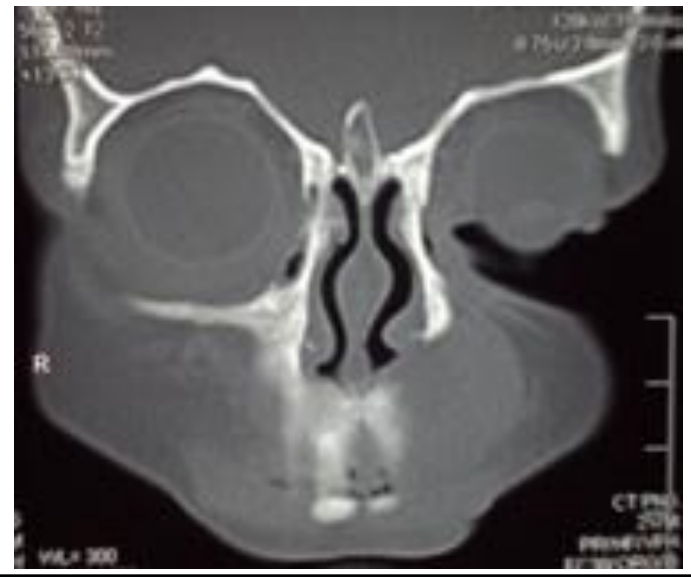

Fig. 1: CT PNS showing homogenous mass involving the left nasolabial area without any bony involvement

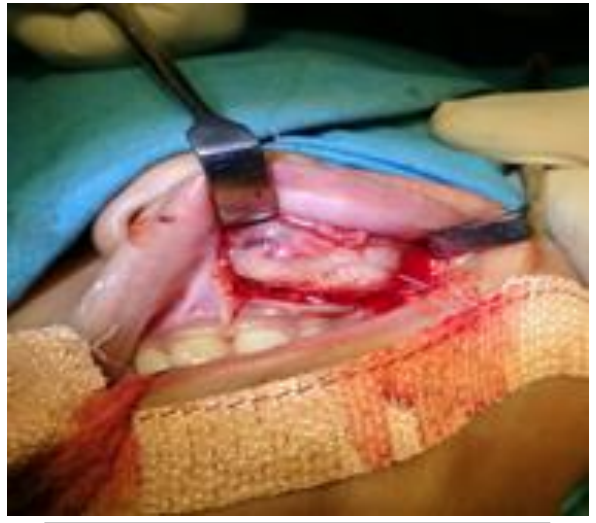

Fig. 2: Intra-oral excision of left nasolabial lesion

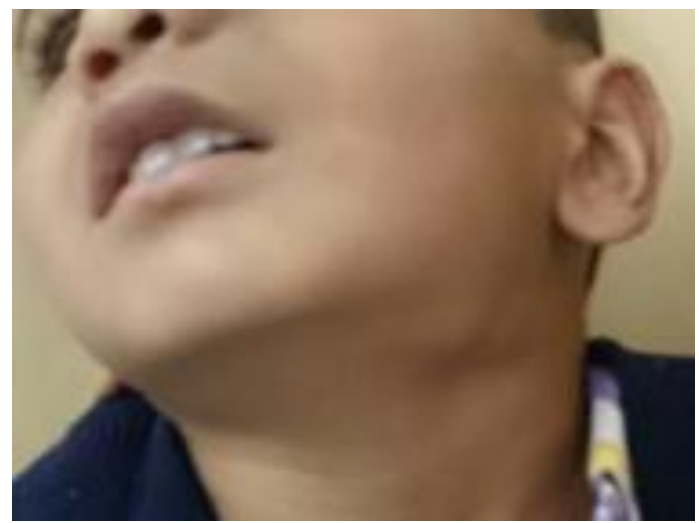

Fig. 3: left submandimandular lymph node 


\section{CASE REPORT}

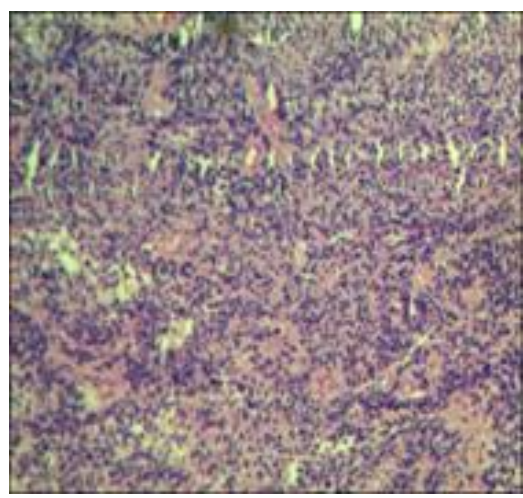

Fig. 4: H\&E staining

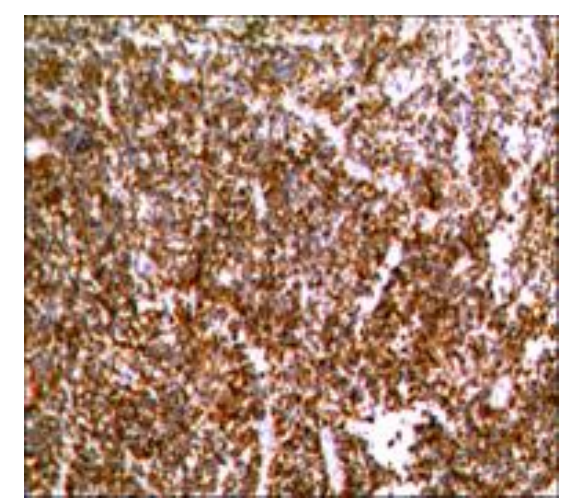

Fig. 5: Non specific enolase

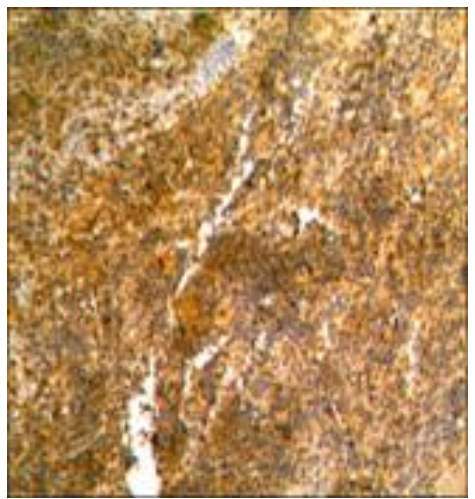

Fig. 6: Tissue positive for desmin

On the basis of light microscopy and IHC, the diagnosis of nasolabial rhabdomyosarcoma was established. The patient was referred to an oncologist and there he was advised 4 cycles of chemotherapy (inj. vincristine, adriamycin \& cyclosphamide) each after every 21 days. He responded well to chemotherapy with resolution of submandibular lymph node.

DISCUSSION: Rhabdomyosarcoma (RMS) is an aggressive malignant skeletal muscle neoplasm of the embryonal mesenchymal tissues, and occurs in a wide variety of sites. The incidence of RMS is usually younger than 15 years, with an incidence peak between 2 to 6 years of age. Approximately 35\% of pediatric RMS occurs in the head and neck region, especially in the nasopharynx, paranasal sinuses, middle ear, mastoid, and facial soft tissues. ${ }^{3}$

In the oral cavity, this neoplasm accounts for $10 \%-12 \%$ of all head and neck RMS, primarily in the tongue, palate, mouth mucosa, and cheek. ${ }^{4}$ Intraosseous lesions are extremely rare ${ }^{8}$. In 1995, the Intergroup Rhabdomyosarcoma Study proposed the "International Classification of Rhabdomyosarcoma," in which 4 main subtypes of RMS were established: 1) botryoid and spindle cell variants of embryonal rhabdomyosarcoma (ERMS) with a favorable prognosis; 2) conventional ERMS with an intermediate prognosis; 3) alveolar rhabdomyosarcoma (ARMS) with a poor prognosis; and 4) undifferentiated sarcomas, also with a poor prognosis ${ }^{5}$. Approximately $60 \%$ of RMS are embryonal (ERMS), and 30\% are of the more aggressive alveolar (ARMS) type. 
The nasolabial region is an unusual site for RMS and only few cases of RMS have been reported. ${ }^{6}$ This tumor usually grows quickly and is infiltrative. It often appears as an enlarged, painless mass. Initial symptoms may be vague and are occasionally associated with pain, trismus, paresthesia, facial palsy, aural or nasal discharge, or may mimic other childhood and adolescent soft tissue sarcomas. Because of the wide variation of clinical features, this lesion is often initially misdiagnosed.7

Unfortunately, RMS frequently produces distant metastases, which are associated with poor survival ${ }^{8}$, although a wide range of behavior is seen. ${ }^{9}$ Multidrug, multicycle, dose-intensive chemotherapy combined with radiotherapy and wide surgical resection when feasible improves survival rates in children ${ }^{10}$. In the present case, because the lesion was primary and there was no osseous involvement, the treatment was based only on chemotherapy.

The effect of radiation therapy or chemotherapy on sarcomas is debatable. Some studies show that patients $<19$ years of age treated by surgery alone have a favorable prognosis; therefore, this may be recommended as the initial treatment in young patients when the tumor is resectable. ${ }^{8}$ The use of intensity-modulated radiation therapy in the treatment of pediatric malignancies is controversial. Radiofrequency ablation is a possible method of treatment in cases of recurrent RMS and shows promising results.

CONCLUSION: The present report describes the case of a patient with RMS in the nasolabial region limited to soft tissues. It presented as an asymptomatic expansile lesion, which, when examined both clinically and with radiographical investigation, resembled a simple nasolabial cyst. We emphasize the importance of diagnosis and medical care to detect any fast-growing lesions in children and to establish an appropriate treatment plan aimed at improving prognosis and patient survival.

\section{REFERENCES:}

1. Wesley RK, Scannell T, Nathan LE. Nasolabial cyst: presentation of a case with a review of the literature. J Oral Maxillofac Surg 1984; 42: 188-92.

2. Nixdorf DR, Peters E, Lung KE. Clinical presentation and differential diagnosis of nasolabial cyst. J Can Dent Assoc 2003;69:146-9.0000E 316 Libório et al. March 2009.

3. Som PM, Norton KI. Lesions that manifest as medial cheek and nasolabial fold masses. Radiology 1991; 178: 831-5.

4. Waldron CA, el-Mofty SK, Gnepp DR. Tumors of the intraoral minor salivary glands: a demographic and histologic study of 426 cases. Oral Surg Oral Med Oral Pathol Oral Radiol Endod 1988; 66: 323-33.

5. Wiener ES. Head and neck rhabdomyosarcoma. Semin Pediatr Surg 1994; 3: 203-6.

6. Escapa Garrachón J, Martín Peña F, Alonso Treceño JL, Represa J. Childhood rhabdomyosarcoma of nasolabial localization. A propos of a case. An Otorrinolaringol Ibero Am 1992; 19:27-33.

7. Khoshy M, Paulino AC, Marcus RB Jr, Ting JY, Whitaker D, Davis LW. Extra-target doses in children receiving multileaf collimator (MLC) based intensity modulated radiation therapy (IMRT). Pediatr Blood Cancer 2004; 42:626-30.

8. McDowell HP. Update on childhood rhabdomyosarcoma. Arch Dis Child 2003; 88:354-7.

9. Brookes CN, Van Veizen D. Rhabdomyosarcoma presenting as a facial swelling in a child. A case report and review of literature. Br J Oral Maxillofac Surg 1990; 28:117-21. 
10. Chi AC, Barnes JD, Budnick S, Agresta SV, Neville B. Rhabdomyosarcoma of the maxillary gingiva. J Periodontol 2007; 78: 1839-45.

\section{AUTHORS:}

1. Ashfaque Ansari

2. Rajeev Pastapur

3. Suma Moni Mathew.

\section{PARTICULARS OF CONTRIBUTORS:}

1. Assistant Professor, Department of ENT, MGM Medical College \& Hospital, Aurangabad.

2. Assistant Professor, Department of ENT, MGM Medical College \& Hospital, Aurangabad.

3. Resident, Department of ENT, MGM Medical College \& Hospital, Aurangabad.

\section{NAME ADDRESS EMAIL ID OF THE} CORRESPONDING AUTHOR:

Dr. Ashfaque Ansari,

Assistant Professor,

Department of ENT \& Neck Surgery,

MGM Medical College \& Hospital,

Aurangabad.

E-mail: ashfaque.dr@gmail.com

Date of Submission: 26/03/2014.

Date of Peer Review: 27/03/2014.

Date of Acceptance: 03/04/2014.

Date of Publishing: 15/04/2014. 